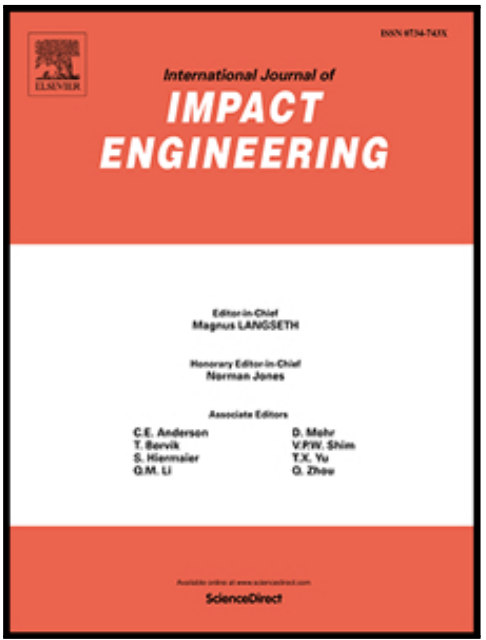

Influence of Global Stiffness and Equivalent Model on Prediction of Impact Response of RC Beams

Thong M. Pham , HongHao

PII:

DOI:

Reference:

To appear in:

Received date:

Revised date:

Accepted date:
S0734-743X(17)30428-1

10.1016/j.jijmpeng.2017.11.014

IE 3023

International Journal of Impact Engineering

15 May 2017

24 November 2017

24 November 2017

Please cite this article as: Thong M. Pham , HongHao, Influence of Global Stiffness and Equivalent Model on Prediction of Impact Response of RC Beams, International Journal of Impact Engineering (2017), doi: 10.1016/j.ijimpeng.2017.11.014

This is a PDF file of an unedited manuscript that has been accepted for publication. As a service to our customers we are providing this early version of the manuscript. The manuscript will undergo copyediting, typesetting, and review of the resulting proof before it is published in its final form. Please note that during the production process errors may be discovered which could affect the content, and all legal disclaimers that apply to the journal pertain. 


\section{HIGHLIGHTS}

- Analytical model for prediction of impact response

- Global stiffness does not affect the impact force

- Roles of local and global stiffness in the impact response at difference phases

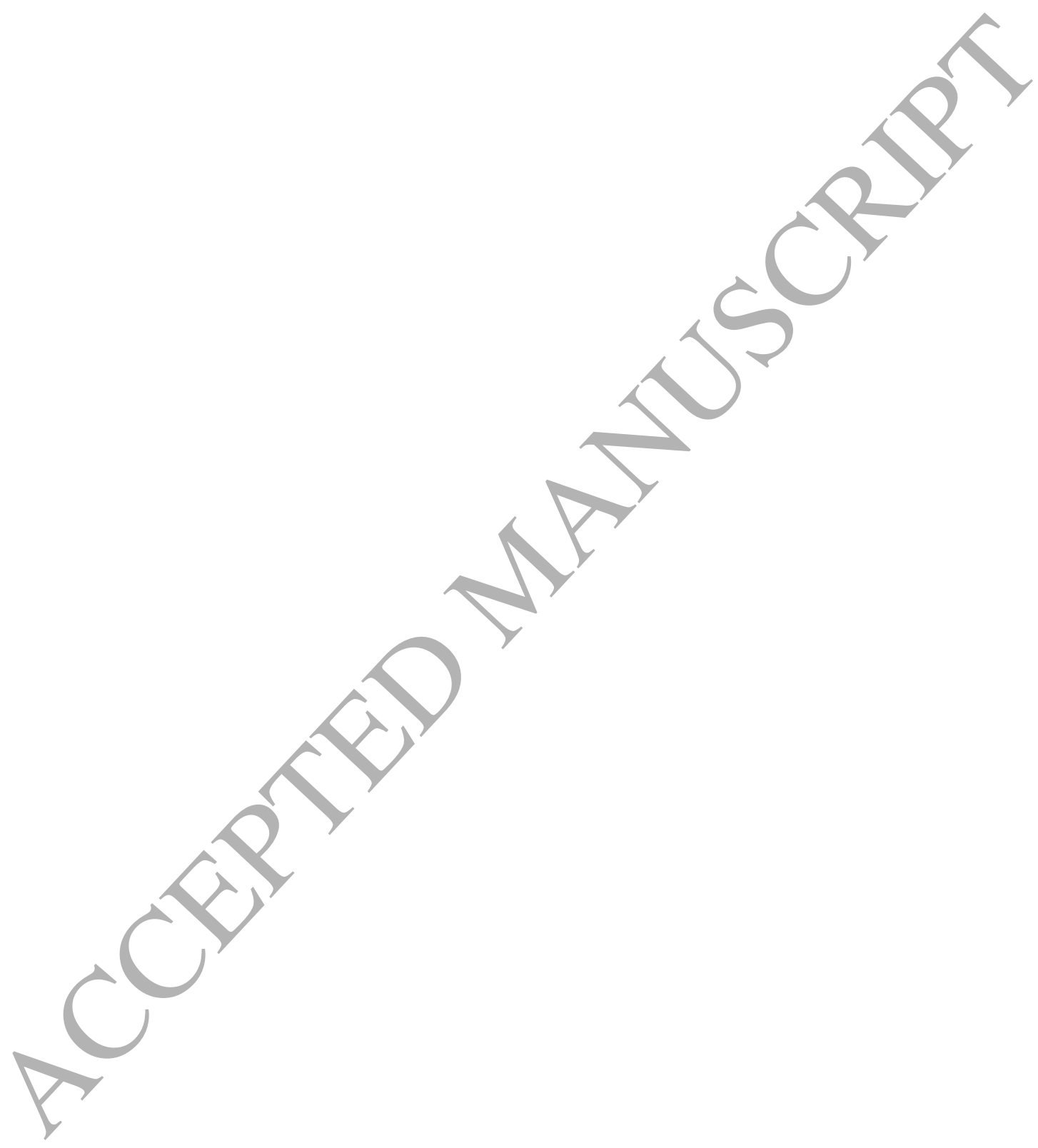




\title{
Influence of Global Stiffness and Equivalent Model on Prediction of Impact Response of RC Beams
}

\author{
Thong M. Pham ${ }^{1}$ and Hong $\mathrm{Hao}^{2}$
}

\section{Abstract}

A spring-mass model is commonly used to predict the impact response of a beam. This type of models usually assumes the beam response is governed by flexural and/or shear response mode in deriving the equivalent structural parameters, i.e. equivalent stiffness and mass. However, it is also well-known that under high-speed impact the response during the impact could be limited to a localized area around the impact point. For such cases, the equivalent stiffness and mass estimated from the global response of the beam do not necessarily give good predictions of beam responses. This study numerically and analytically investigates the effect of the stiffness on the impact behavior of reinforced concrete (RC) beams. The numerical results have shown that the stiffness estimated from the global response does not reflect the true behavior of the beam during the first impact impulse. However, the stiffness governs the behavior of the beams at the final loading and free-vibration phase as the global mode dominates the response. Interestingly, a free beam, which has no boundary constraint, and the reference beam with boundary constraint show an identical behavior during the first impact impulse, demonstrating the impact response of the beam in the initial stage is

\footnotetext{
${ }^{1}$ Research Fellow, Center for Infrastructural Monitoring and Protection, School of Civil and Mechanical Engineering, Curtin University, Kent Street, Bentley, WA 6102, Australia. Email: thong.pham@curtin.edu.au

${ }^{2}$ John Curtin Distinguished Professor, Center for Infrastructural Monitoring and Protection, School of Civil and Mechanical Engineering, Curtin University, Kent Street, Bentley, WA 6102, Australia (corresponding author). Email: hong.hao@curtin.edu.au
} 
independent of the beam global stiffness. In addition, an analytical model is proposed to predict the impact response of RC beams with reasonable agreement.

Keywords: Spring-mass model; Impact loading; Impact response; Flexural stiffness; Shear resistance; RC beams.

\section{Introduction}

Predicting the impact behavior of reinforced concrete $(\mathrm{RC})$ structures remains a challenging task for not only engineers but also researchers. The impact behavior of RC beams has been investigated by previous studies [1-4]. The behavior of a structure subjected to impact loads includes both the global response and the local response. The impact behavior and failure of concrete structures also depend on the impact force amplitude and the ratio $\left(t_{d} / T\right)$ of the loading duration to the fundamental vibration period of the structure. If this ratio $\left(t_{d} / T\right)$ is very small, the structural response is primarily governed by stress wave propagation and the inertia resistance plays an essential role in resisting the impact load. On the other hand, when the ratio $\left(t_{d} / T\right)$ is large, the structural response is a quasi-static mode and associated with the stiffness [5]. Researchers over the world have been spending efforts to predict the impact behavior. Among all these studies the spring-mass model is the most common approach to tackle this problem [6-9]. The essence of this type of models is the stiffness of the spring in which the linear and nonlinear behavior can be incorporated. In these models, the spring stiffness can reflect the flexural and shear behavior in a single manner or in its combination form [10-13]. Results from these studies showed that the stiffness determined from the global response and the boundary condition shows a close prediction of the impact behavior. 
Meanwhile, there is a consensus that a plastic hinge may be formed and travel along the beam if it is excessively struck by a projectile [14]. In general, the plastic hinge in a beam occurs when the maximum bending moment is equal to the full plastic bending moment of the beam and it can be straightforwardly estimated from the beam cross section and material properties $[15,16]$. The formation and propagation of a plastic hinge are presented in details in the study by Jones [17]. In these studies, the plastic hinge has been proven to influence the impact behavior of a beam. Pham and Hao [18] have stated that only a portion of a beam vibrates during the early stage of an impact event while the remaining part of the beam is still stationary. In addition, Pham and Hao [19] conducted a numerical study about the effect of the plastic hinge on the impact behavior of RC beams. The authors concluded that the plastic hinge location should be taken into consideration when determining the stiffness of a beam for deriving an equivalent single degree of freedom (DOF) for predicting the impact load, while most studies and some design guides determine the stiffness of the equivalent system based on the global stiffness of the beam. Different approaches exist in deriving the equivalent spring-mass system for predicting the impact response of a structure, but there is no systematic study yet that investigates the influence of these different approaches on the accuracy of the derived equivalent models. Therefore, the influence of taking the whole effective span or only between plastic hinges as previously discussed in deriving the equivalent spring-mass system on impact response prediction needs be examined.

An equivalent mass also needs to be identified when deriving a SDOF system. There are different approaches to determine the equivalent mass of a system. Biggs [20] estimated the equivalent mass from the mass density and the assumed deflected shape of the structure. This approach was later adapted by Sha and Hao [21] to model impact on a cantilever column. Wu and $\mathrm{Yu}[8]$ equated the fundamental frequency of a structure to that of the SDOF system to determine the equivalent mass. Abrate [6] determined the equivalent mass of the SDOF is 
equal to one-fourth of the total mass of the plate. Gao et al. [22] estimated the equivalent mass regarding the actual mass of a plate and its rotation angle. The authors also recommended that the equivalent mass in their model is used only in the post-yielding stage. The equivalent mass is dependent on the deflected shape of a structure and assumptions that are used to derive the model.

This study conducts a numerical investigation on the effect of the flexural stiffness and shear capacity of RC beams on its impact behavior. The results of this study are able to answer whether considering the whole effective span of a structure to determine the equivalent stiffness is appropriate for a SDOF model to predict the impact response.

\section{Spring-mass model}

In the literature, simplified spring-mass systems are often used to model a dynamic problem. In general, a two DOF spring-mass model has two springs in which the stiffness of the structure is modeled by $k_{1}$ while $k_{2}$ is the representative for the local indentation. The equations of motion can be written as [9]:

$$
\begin{aligned}
& m_{1} \ddot{x_{1}}+k_{1}\left(x_{1}-x_{2}\right)=0 \\
& m_{2} \ddot{x_{2}}+k_{2} x_{2}+k_{1}\left(x_{2}-x_{1}\right)=0
\end{aligned}
$$

where $x_{1}$ and $x_{2}$ are respectively movements of the projectile and the beam, $m_{1}$ and $m_{2}$ are the masses of the projector and the beam, respectively.

A spring-mass model often assumes the resistance of a structure to be representative by a spring. Based on the failure mechanism, the stiffness can be estimated depending on the actual behavior of the structure (flexural and/or shear manner) [10-13]. Modeling a structure by using a spring-mass model may yield a reliable prediction if the loading rate is not very high, for example, earthquake related problems. A simplified spring-mass model may provide 
a close prediction if the global response mode is dominant $[5,18,19]$. Similarly, a simplified spring-mass model is able to yield a reliable prediction of the displacement of the high loading rate problems (e.g. impact loads and close-in blast loads) if the global response mode is govern the total response. It is worth mentioning that under impact or close-in blast loads, a structure response may be governed by a localized response mode during the forced response phase and by global response mode only in the free-vibration phase.

Moreover, a spring-mass system often separately models the shear failure and flexural failure. This common approach is usually reasonable because the two failure modes normally do not take place at the same time. A beam will enter the flexural response mode only when it can sustain the shear failure [11]. It is noted that the direct shear failure, which usually happens near the supports, are likely to happen in problems associated with high loading rate. The decoupling of the flexural and direct shear responses in SDOF analysis can be found in the study by Krauthammer et al. [23]. Meanwhile, loosely coupled SDOF systems considering both the flexural failure mode and the direct shear failure were justified by previous studies $[11,24] . \mathrm{Xu}$ et al. [24] adopted loosely coupled SDOF systems that consider both the flexural failure and the direct shear failure to predict the structural response under blast loads. The interaction between the direct shear and flexural responses of RC structures was investigated.

As can be seen the stiffness of a structure is utilized to predict its impact behavior. This stiffness can be estimated according to the flexural or shear mode and is related to the global response of the structure. In reality, however, the response of a structure subjected to impact load might be localized during the forced phase immediately after the impact initiation. Modelling the structural responses based on the assumption of global flexural and/or shear response therefore may lead to inaccurate predictions. The influence of this discrepancy between the assumption and the reality on impact response predictions has not been 
investigated yet. This is the topic of the present study. In order not to limit to any particular cases, in the present study the stiffness of beams is largely varied to investigate its impact behavior. The stiffness of the beams is changed by varying the reinforcement ratio, the effective span, and the boundary condition.

\section{Numerical simulation}

\subsection{Numerical model}

There have been a few numerical studies about the impact problem $\{4,25,26]$. Ožbolt and Sharma [4] conducted a numerical simulation on the impact behavior of RC beams. The authors concluded that RC beams with varied shear reinforcement ratios had similar shear failure at the impact point and the dynamic reactions were independent on the amount of shear reinforcement. Saatci and Vecchio [26] proposed a nonlinear finite element analysis procedure employing the disturbed stress field model to model the impact problem. The authors aimed to propose a new nonlinear finite element analysis and verify it against testing data. The numerical results showed a well match with the experimental results although the strain rate effect was not considered. Cotsovos et al. [25] conducted a brief review on the experimental and numerical stúdies on impact problems. The authors carried out a numerical investigation on high loading rate problems but not a specific impact problem. The effect of the loading rate on the structural behaviors of $\mathrm{RC}$ beams was investigated, however, the strain rate effect was also not considered.

Meanwhile, the numerical simulation in this study is carried out by using explicit numerical methods coded in the commercial software LS-DYNA [27] which considers the strain rate effect. This software has been widely adopted to examine the structural responses associated with large deformation, structural response to impact and blast loads, and strain rate behavior 
of materials. Particularly, the software has been proven yielding reliable numerical predictions of structural response to impact loads $[18,19]$.

A numerical model is developed in LS-DYNA and validated against the experimental impact tests by Pham and Hao [28]. The tested beam had a rectangular section of $150 \times 250 \mathrm{~mm}^{2}$, the beam length of $2.2 \mathrm{~m}, 2 \mathrm{D} 10$ and 2D12 rebars as longitudinal reinforcement, and stirrups of D10 plain bars at the spacing of $125 \mathrm{~mm}$. 3-nodes beam elements (BEAM_161) with 2 x 2 Gauss quadrature integration are employed to model reinforcements while concrete and steel plates are modeled by 8-nodes constant stress solid element (SOLID 164) with 1-point quadrature integration. Since no slip between concrete and reinforcements was observed in the experiment, a perfect bond between reinforcements and surrounding concrete is assumed in this simulation. The convergence test is conducted by halving the mesh size. The numerical results have shown that the numerical simulation converged as the mesh size is $10 \mathrm{~mm}$. Further reducing the element size only had insignificant influence on the numerical results but increased the computing time and the risk of the computer memory overflow. Thus, $10 \mathrm{~mm}$ mesh size is used in this numerical model.

The simply support condition in the experiment was carefully designed and detailed in the previous studies $[28,29]$. Steel plates and rollers were used to create the simply support condition as described in Fig. 1. To ensure the unity of the boundary condition in the numerical model and the experimental test, the actual structure of the support is simulated in the numerical model with the entire experimental set-up including the steel plates and rollers. Accurately modelling the boundary condition in the finite element model was found to be essential for yielding reliable numerical results as presented in the previous study by Villavicencio and Guedes Soares [2]. Fig. 2 shows details of the numerical model and the supports. The penalty contact algorithm *Automatic_Surface_to_Surface is used to simulate 
the contacts between steel plates, steel rollers, and the concrete beam at the supports. The contact algorithm can significantly affect the impact force and thus the impact behavior of the beam. Parameters related to the contact algorithm has been chosen with care based on a previous study about the sensitivity of the contact stiffness on the impact behavior of RC beams by Pham et al. [30].

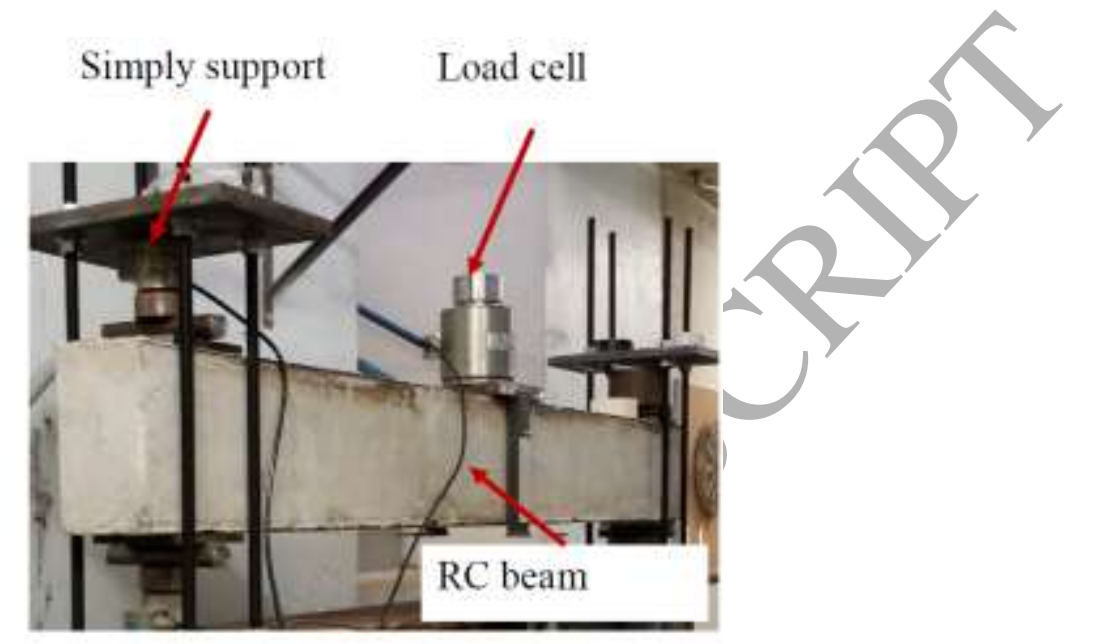

Figure 1. Experimental test setup

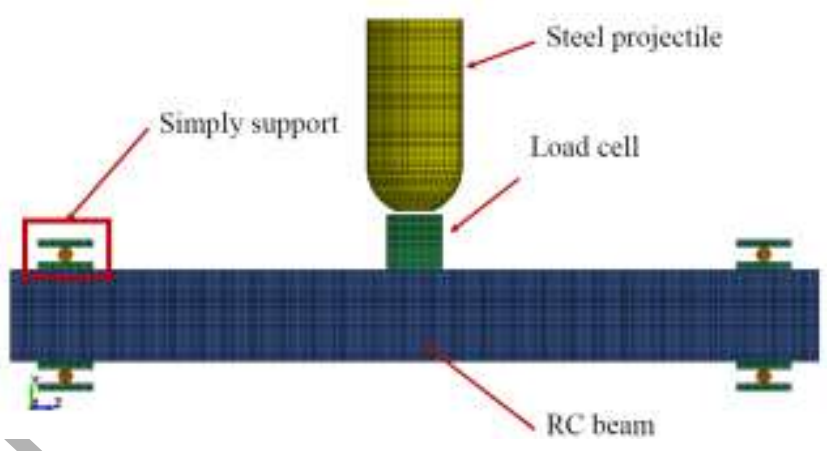

Figure 2. Modelling of the RC beam

\subsection{Material model}

There are a number of constitutive models (e.g. MAT 16, 25, 72, 84/85, and 159) incorporated in LS_DYNA to represent concrete behavior under impact and blast loads. Some of these available models have been adopted to simulate concrete against impact loads and their verification has been confirmed by previous studies [31-33]. In this study, the material model *Mat_Concrete_Damage_Rel3 (MAT_72_REL3) is used to simulate the concrete 
behavior. The strain-rate effect, plasticity, and damage softening after failure have been taken into consideration in this material model. Previous studies have shown that this material model yielded a reliable numerical prediction of concrete structures against impact and blast loads [33-36]. In this study the concrete material has a compressive strength of $46 \mathrm{MPa}$ as listed in Table 1. Meanwhile, steel reinforcements are simulated by using the material model *Mat_Piecewise_Linear_Plasticity (MAT_24). This material model considers the isotropic and kinematic hardening plasticity of the material. It also allows user defined parameters for the stress-strain curve and the strain rate curve.

Table 1. Parameters for the numerical model

\begin{tabular}{|c|c|c|c|}
\hline Material & Model in LS-DYNA & Input parameter & Value \\
\hline Concrete & $\begin{array}{l}\text { CONCRETE_DAMAGE_RE } \\
\text { L3 (MAT_72R3) }\end{array}$ & $\begin{array}{l}\text { Density } \\
\text { Compressiye strength } \\
\text { Poisson's ratio }\end{array}$ & $\begin{array}{l}2160 \mathrm{~kg} / \mathrm{m}^{3} \\
46 \mathrm{MPa} \\
0.2\end{array}$ \\
\hline Reinforcing bar & $\begin{array}{l}\text { PIECEWISE_LINEAR } \\
\text { STICITY (MAT_024) }\end{array}$ & $\begin{array}{l}\text { Density } \\
\text { Modulus of elasticity } \\
\text { Poisson's ratio } \\
\text { Yield stress } \\
\text { Tangent modulus } \\
\text { Failure strain }\end{array}$ & $\begin{array}{l}7800 \mathrm{~kg} / \mathrm{m}^{3} \\
200 \mathrm{GPa} \\
0.3 \\
500 \mathrm{MPa} \\
2 \mathrm{GPa} \\
0.15\end{array}$ \\
\hline $\begin{array}{l}\text { Steel plates, } \\
\text { rollers, load cell } \\
\text { and projectile }\end{array}$ & ELASTIC (MAT_1) & $\begin{array}{l}\text { Density } \\
\text { Modulus of elasticity } \\
\text { Poisson's ratio }\end{array}$ & $\begin{array}{l}7800 \mathrm{~kg} / \mathrm{m}^{3} \\
200 \mathrm{GPa} \\
0.3\end{array}$ \\
\hline
\end{tabular}

\subsection{Strain rate effect}

Different from the quasi-static scenario, the inertia and strain-rate effects are dominant factors to the structural response under impact and blast loads. In such loading cases, both concrete and steel may/respond at very high strain rates in the order of $10-1000 \mathrm{~s}^{-1}$. The strength of these materials corresponding to high strain rates can be significantly higher than the corresponding strengths under static loads [37]. Malvar [38] conducted a review of experimental tests which shows that the strength increase of the steel reinforcement can be up to more than $50 \%$. Meanwhile, the corresponding increase in the compressive and tensile strength of concrete under high strain rate could be up to $100 \%$ and $600 \%$, respectively [39]. 
Therefore, the strain rate effect of concrete and steel reinforcement needs to be taken into consideration in the simulation to ensure reliable numerical results. The relationship between the tensile and compressive DIF of steel and strain rate is defined by the following equations [40]:

$$
\begin{aligned}
& D I F=\left(\frac{\dot{\varepsilon}}{10^{-4}}\right)^{\alpha} \\
& \alpha=0.074-\frac{0.04 f_{y}}{414}
\end{aligned}
$$

where $f_{y}$ is the yield strength of steel in MPa and $\varepsilon$ is the strain rate of steel.

The strength increment at a given strain rate is defined by the dynamic increase factor (DIF). In the literature, there are many empirical models quantifying the strain rate effect of concrete and steel. The use of the strain rate effect in the problems associated with high strain rate was proven to yield reliable predictions [35-37]. The strength increase of materials at high strain rate is resulted from the nature of the materials and inertia effect. Most of DIF models were derived directly from testing data therefore they have not distinguished the effect of the two factors. Hao and Hao [37] have proposed a DIF relation, in which the lateral inertia effect on strength increase has been removed, for concrete behavior under high loading rates. The accuracy of the proposed model has been experimentally verified by the split Hopkinson pressure bar tests [41]. The DIF relations used in this study are presented in the following expressions [37]:

$$
\begin{gathered}
C D I F=\frac{f_{c d}}{f_{c s}}=0.0419\left(\log \dot{\varepsilon}_{d}\right)+1.2165 \text { for } \dot{\varepsilon}_{d} \leq 30 / s \\
C D I F=\frac{f_{c d}}{f_{c s}}=0.8988\left(\log \dot{\varepsilon}_{d}\right)^{2}-2.8255\left(\log \dot{\varepsilon}_{d}\right)+3.4907 \text { for } \dot{\varepsilon}_{d}>30 / s \\
T D I F=\frac{f_{t d}}{f_{t s}}=0.26\left(\log \dot{\varepsilon}_{d}\right)+2.06 \text { for } \dot{\varepsilon}_{d} \leq 1 / s
\end{gathered}
$$




$$
\begin{aligned}
& T D I F=\frac{f_{t d}}{f_{t s}}=2\left(\log \dot{\varepsilon}_{d}\right)+2.06 \text { for } 1<\dot{\varepsilon}_{d} \leq 2 / s \\
& T D I F=\frac{f_{t d}}{f_{t s}}=1.4431\left(\log \dot{\varepsilon}_{d}\right)+2.2276 \text { for } \dot{\varepsilon}_{d}>2 / s
\end{aligned}
$$

where $C D I F$ and TDIF are the DIF for concrete in compression and tension, respectively; $f_{c d}$ and $f_{c s}$ are the compressive strength of concrete at high strain rate and quasi-static loads, respectively; $f_{t d}$ and $f_{t s}$ are the tensile strength of concrete at high strain rate and quasi-static loads, respectively; and $\dot{\varepsilon}_{d}$ is the strain rate of concrete.

\subsection{Model verification}

The numerical simulation results are verified against the experimental results as shown in Figs. 3-4. Fig. 3 shows the plastic strain along the beam, in which high plastic strain occurs at the mid-span of both the experiment and numerical simulation. Concrete damage at the impact point is observed in both numerical and experimental results. Similar to the experimental results, both the shear failure and flexural failure are seen in the numerical model. The two major shear cracks can also be seen in the experiment and the simulation.

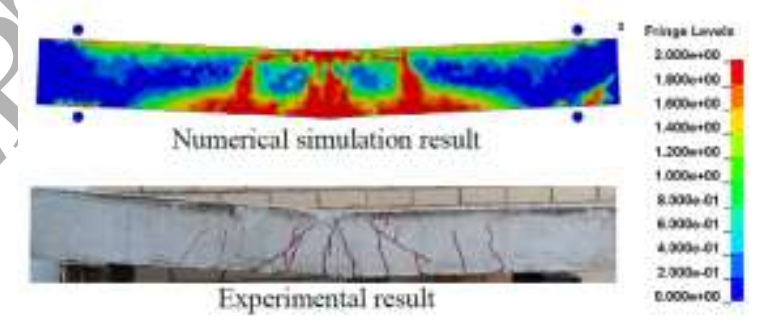

Figure 3. Plastic strain vs failure of the tested beams 

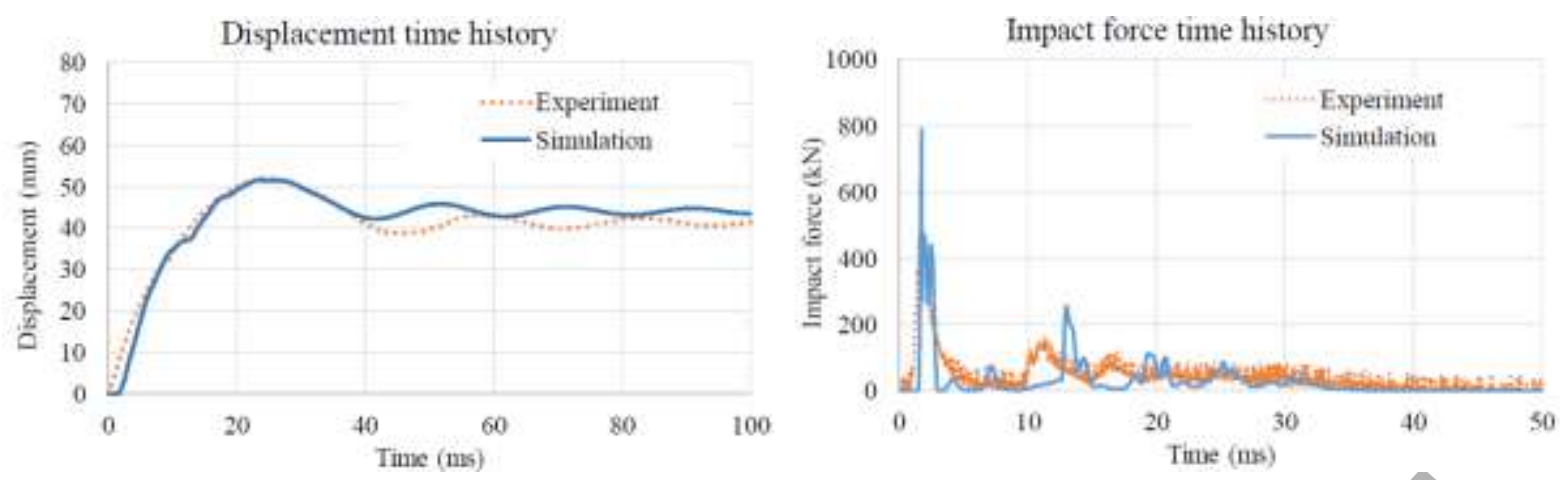

Figure 4. Time histories of displacement and impact force

Fig. 4 shows the time histories of the mid-span displacement and the impact force. In the experiment, the maximum and residual displacements were 52 and $42 \mathrm{~mm}$, respectively. As can be seen in Fig. 4, the experimental results agree well with the numerical simulation in which the maximum and residual displacements are 52 and $44 \mathrm{~mm}$, respectively. Fig. 4 also shows that the impact forces from the experiment and the numerical simulation agree well. The impact force time history of the beam includes multiple peaks in which the first peak has the largest magnitude followed by multiple peaks with smaller amplitudes. It is noted that the first impulse occurs in the force phase with a very short duration when the beam and the projector are first in contact while the other small impulses are resulted from the interaction between the beam and the projectile after the first impact related to the beam vibration and projectile bouncing. The verification shows that the numerical model yields reliable predictions of the RC beam responses to impact loads.

Shear cracks initiate at about $6 \mathrm{~ms}$ and are well developed at about $10 \mathrm{~ms}$. As can be seen that shear cracks appear and develop after the first impact impulse has ceased and the projectile separated from the beam. At about $3 \mathrm{~ms}$, when the primary impulse of the impact force decays to zero, the displacement at midspan of the beam is about $10 \%$ of its maximum value as shown in Fig. 4. It indicates that the displacement is marginal and is still developing at the end of the first impact. Accordingly, during this impact phase that the projectile is in contact 
with the beam, the bending resistance has not been really activated. Therefore, the flexural stiffness and resistance of the beam are not the primary concern at this instant. Thus, using the flexural stiffness and the resistance of the beam in deriving the spring-mass models to predict the impact force and response may not yield reasonable outcomes.

\section{Numerical results}

To investigate the effects of the flexural stiffness and shear resistance on the impact behavior, intensive numerical simulations have been carried out. The reinforcement ratio, effective span, and the boundary condition are changed to vary the flexural stiffness and the shear resistance of $\mathrm{RC}$ beams in the analyses.

\subsection{Effect of reinforcement ratio}

The longitudinal and shear reinforcements are changed to investigate their effects on the impact behavior of the beam. The longitudinal reinforcements of the reference beam are 2D10 + 2D12. They are replaced by 4D16 and 4D20, leading to the flexural stiffness increase by $93 \%$ and $153 \%$, respectively. Similarly, the shear reinforcement of the reference beam of D10@125 is replaced by D16@125 and D20@125 which results in the shear resistance increase by $98 \%$ and $188 \%$, respectively. It is noted that the shear resistance is estimated based on the procedure presented in the book by MacGregor [42]. The impact force time histories of the beams with different flexural stiffness and shear resistance are presented in Fig. 5. As shown the change in the flexural stiffness and shear resistance does not affect the first impact impulse of these beams but it does influence the following impulses. This finding agrees well with the above discussions on the response of the reference beam. In the duration of first impulse, which occurs within a short period, the displacement of the beam is not really activated. Therefore, the flexural stiffness of the beam has minimum effect on the interaction 
between the projectile and the beam. The interaction of the projectile and the beam depends on the projectile dimension, the contact area and the inertia resistance of the beam. Hence, the beam stiffness does not affect the first impulse. This finding is believed to occur when the impact velocity is sufficiently large, here $6.26 \mathrm{~m} / \mathrm{s}$, and it may not necessarily happen when the impact velocity is low. To clarify the finding at a lower impact velocity, Fig. 6 shows the impact force time histories of these beams when the impact velocity is $1 \mathrm{~m} / \mathrm{s}$. Same observations are obtained, i.e. the similar first impulse while the following impulses are different. Therefore, this finding is valid when the impact velocity is greater than or equal to 1 $\mathrm{m} / \mathrm{s}$. It is also interesting to note that when the impact velocity is $1 \mathrm{~m} / \mathrm{s}$, the peak of the second impulse could be higher than that of the first impulse, and this is more prominent when the flexural stiffness of the beam is higher. This finding can be explained by the local contact stiffness of the beams. When the projectile impacts the beams with a low velocity (here 1 $\mathrm{m} / \mathrm{s}$ ), there is no concrete damage at the impact point so that the contact stiffness of the beam at the second impact is equal to that of the first impact, while the concrete beam has severe damage at the impact point with the impact of $6.26 \mathrm{~m} / \mathrm{s}$ (see Fig. 7). As a result, the contact stiffness of the beam impacted by the $6.26 \mathrm{~m} / \mathrm{s}$ projectile at the second impact is significantly lower than that during the first impact. Therefore, although the second impact associates with the beam rebound, the impact force is smaller because the severely damaged beam reduces the contact stiffness. The higher second impact force observed on the beam impacted by the projectile with $1 \mathrm{~m} / \mathrm{s}$ velocity is because the rebound of the beam, i.e., beam and the projectile move in the opposite direction, and the contact stiffness of the beam remains almost the same as in the first impact. 


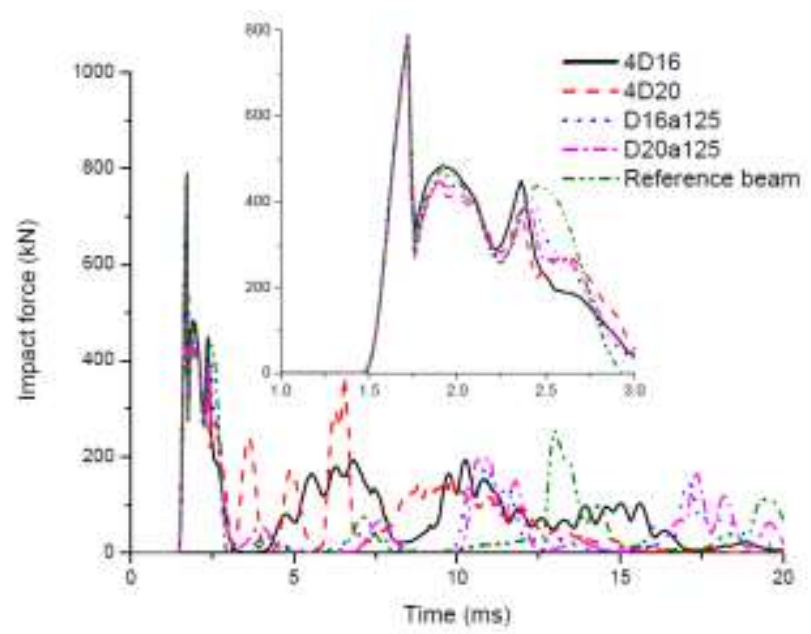

Figure 5. Impact force time histories of beams with varied reinforcement at $6.26 \mathrm{~m} / \mathrm{s}$

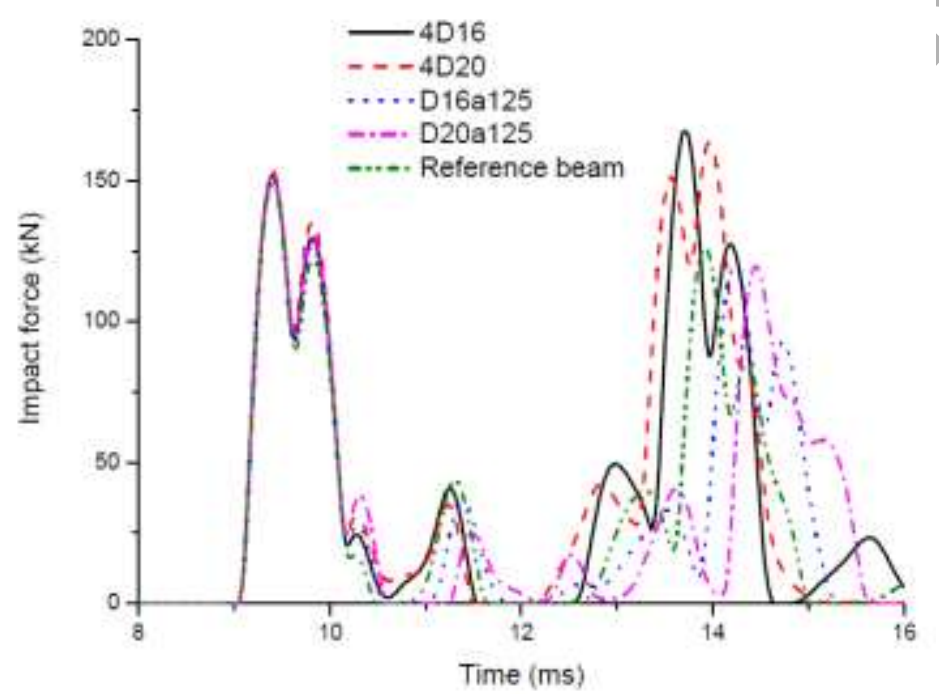

Figure 6. Impact force time histories of beams with varied reinforcement at $1 \mathrm{~m} / \mathrm{s}$

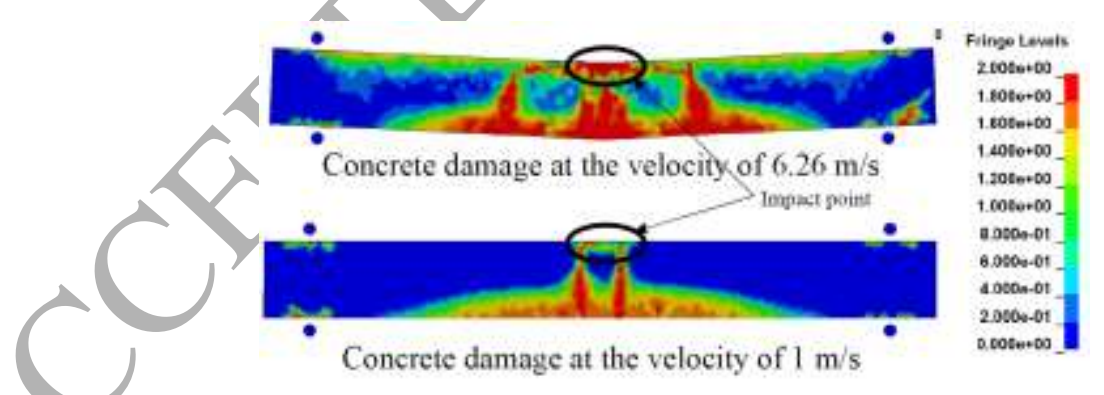

Figure 7. Different concrete damage at different impact velocities

In order to investigate the influence of the natural vibration frequency of the beam on the interaction between the impactor and the beam, the fundamental vibration period of the reference beam is estimated and compared with the numerical results in Figs. 6 and 8. It is well known that the impact force is resulted from the interaction between the projectile and 
the beam, at which the fundamental vibration period may affect this interaction and thus the impact force. Given the reference beam with a square section of 150 x $250 \mathrm{~mm}$, an effective span of $1.9 \mathrm{~m}$, the concrete strength of $46 \mathrm{MPa}$ and simply supported boundary, the fundamental vibration period is approximately $14 \mathrm{~ms}$. As discussed above, this period coincides with the large second impact force as shown in Fig. 6 due to beam rebound. Meanwhile, within each large impact impulse, a few small peaks exist as shown in Figs. 5 and 6. The time interval between these peaks ranges between $0.4 \mathrm{~ms}$ and 1.9 ms. These peaks obviously do not correspond to the beam rebound. They are actually related to the stress wave propagation and reflection in the impactor and the impacted beam. Impacting generates stress waves that propagate in the impactor and beam. When these stress waves reach the boundary they reflect and propagate to the contacting surface between the impactor and the beam. Since the impactor and the beam are still in close contact, the stress waves result in enhancement in the impact force. Given the height of the projectile $(0.55 \mathrm{~m})$, the height of the load cell $(0.15$ $\mathrm{m})$, the height of the beam $(0.25 \mathrm{~m} / \mathrm{s})$, the stress wave velocity in steel $(5000 \mathrm{~m} / \mathrm{s})$, and the stress wave velocity in concrete $(3500 \mathrm{~m} / \mathrm{s})$, a stress wave needs about $0.42 \mathrm{~ms}$ to travel through the projectile, the load cell, and the beam and then reflects back. This time interval is similar to the time interval between the local peak impact forces as mentioned above.

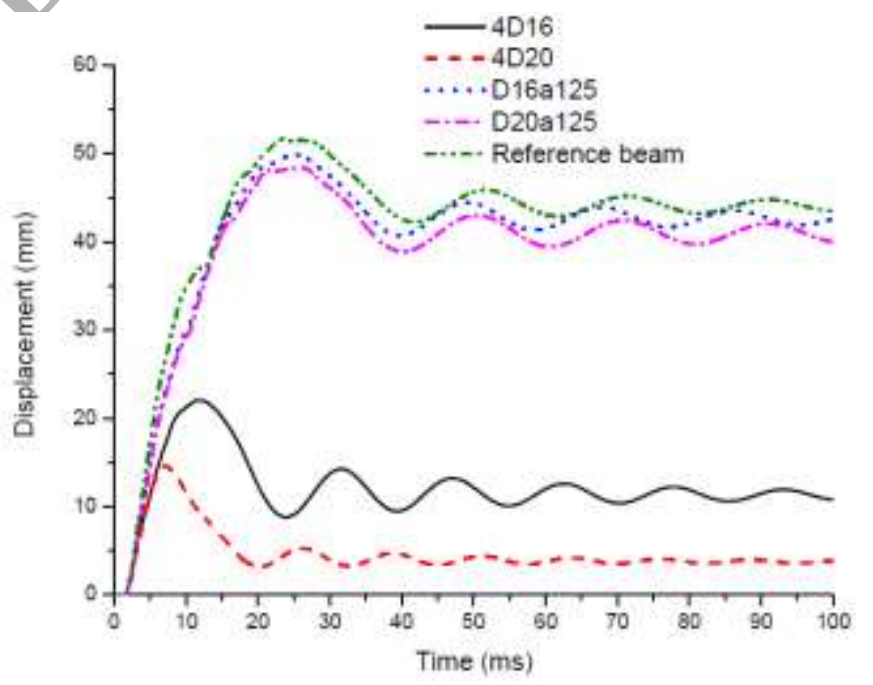


Figure 8. Displacement time histories of beams with varied reinforcement impacted by the impactor at $6.26 \mathrm{~m} / \mathrm{s}$

The mid-span displacements of these beams subjected to the impact velocity of $6.26 \mathrm{~m} / \mathrm{s}$ are also recorded and the results are shown in Fig. 8. As expected, changing the shear resistance does not affect the midspan displacement of these beams while increasing the flexural stiffness significantly reduces the midspan displacement. It is noted that this statement is applied to beams which have the midspan displacement governed by the flexural stiffness. Unlike the impact force that takes place in a very short period (2-3 ms), the vibration occurs in the free vibration phase lasting for about $100 \mathrm{~ms}$. The beam greatly deforms in this period and thus the deflection is affected by the stiffness. In addition, the deflection of the beam is dominated by the flexural action rather than shear action so that increasing the shear resistance only slightly reduces the displacement as shown in Fig. 8. The positive reaction at the supports occurs when the first impact impulse has gone and the beam stiffness goes into effect so that the beams with higher stiffness is expected to yield larger reaction forces. As expected, beams with 4D16 and 4D20 show higher reaction forces as compared to that of the reference beam as shown in Fig. 9 .

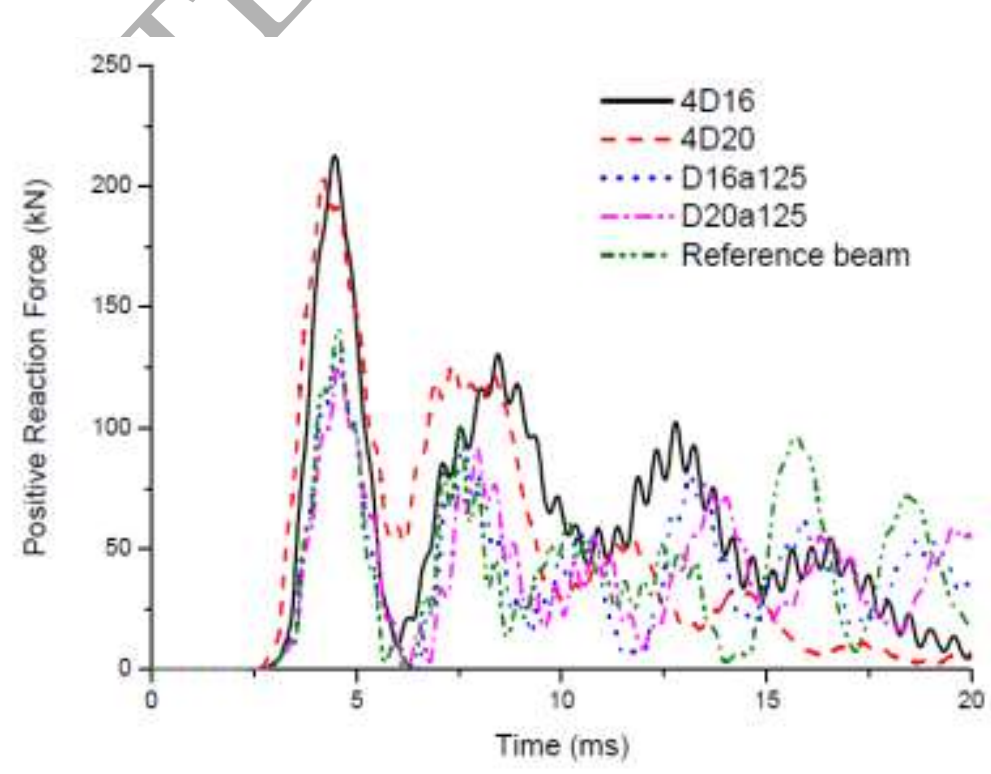


Figure 9. Positive reaction force time histories of beams with varied reinforcement corresponding to the impact velocity $6.26 \mathrm{~m} / \mathrm{s}$

\subsection{Effect of span}

Flexural stiffness directly relates to the effective span of a beam so that it is changed in this study to vary the flexural stiffness of the beam. The effective span of the reference beam (1.9 $\mathrm{m})$ is varied to $1.5 \mathrm{~m}, 1.1 \mathrm{~m}$, and $0.9 \mathrm{~m}$. Fig. 10 shows the impact force time histories of the beams with different spans. In general, the change of the beam span does not really affect the first impact impulse but it results in significant variation in the following impulses. The similar behavior at the first impact impulse may be resulted from the identical contact stiffness and interaction between the projectile and the impacted area. As previously presented, the change of the span leading to different flexural stiffness of the beams did not affect the beams' behavior during the first impulse. After the first impulse has passed, the effect of the global stiffness of the beams become more dominant to the impact behavior. It is worth mentioning that the following impulses are resulted from the interaction of the projectile and the beams at which the rebound of the beam dominates to these impulses. Therefore, the shorter beams which have higher natural frequency and shorter duration will rebound faster. Therefore, the second impulse occurs faster when the beam has higher stiffness, i.e., higher frequency, because it rebounds quicker. For example, Fig. 10 shows the order of the beams with span $0.7 \mathrm{~m}$, span $1.1 \mathrm{~m}$, span 1.5 , and span of $1.9 \mathrm{~m}$, respectively. 


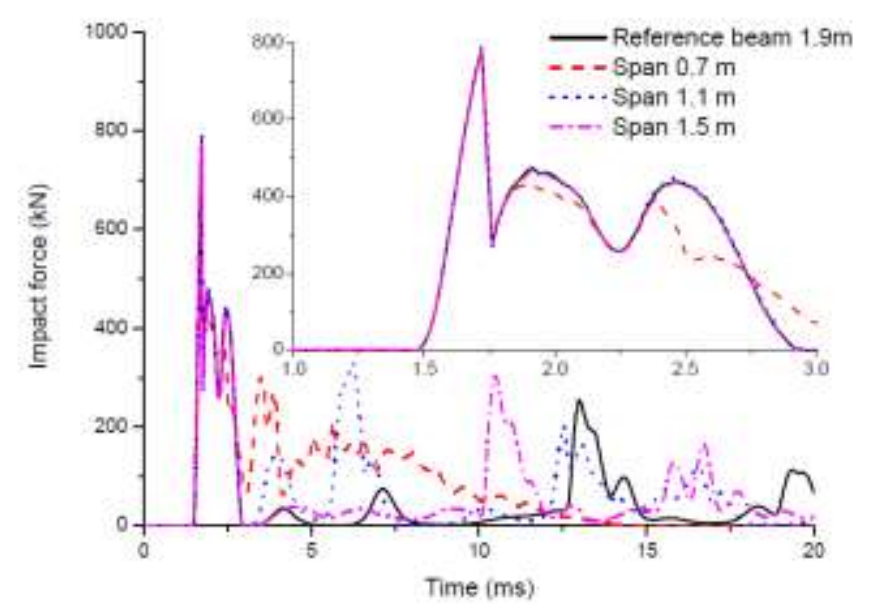

Figure 10. Impact force time histories of beams with varied span subjected to $6.26 \mathrm{~m} / \mathrm{s}$ impact

Further careful investigation into the first impact impulse has been carried out and it reveals that the first impact impulse is not affected if the span changes from $1.9 \mathrm{~m}$ to $1.1 \mathrm{~m}$. The first impact impulse has a marginal variation when the span reduces to $0.7 \mathrm{~m}$ as shown in Fig. 10 . This finding is based on the impact velocity of $6.26 \mathrm{~m} / \mathrm{s}$ and it is not necessarily correct in cases of lower impact velocities. When the impact velocity is low, the boundary condition may have more effect on the first impulse [19]. Fig. 11 thus shows the impact force time histories of the beams with varied spans subjected to the impact velocity of $1 \mathrm{~m} / \mathrm{s}$. These beams also have the similar first impact impulse, indicating that the span does not influence the first impulse at a velocity as low as $1 \mathrm{~m} / \mathrm{s}$. This finding can be explained by the definition of the relatively long beam as proposed by Pham and Hao [19] and presented in the discussion. It is noted that a relatively long beam has a span long enough so that the stationary point has not reached the boundary at the peak impact force. 


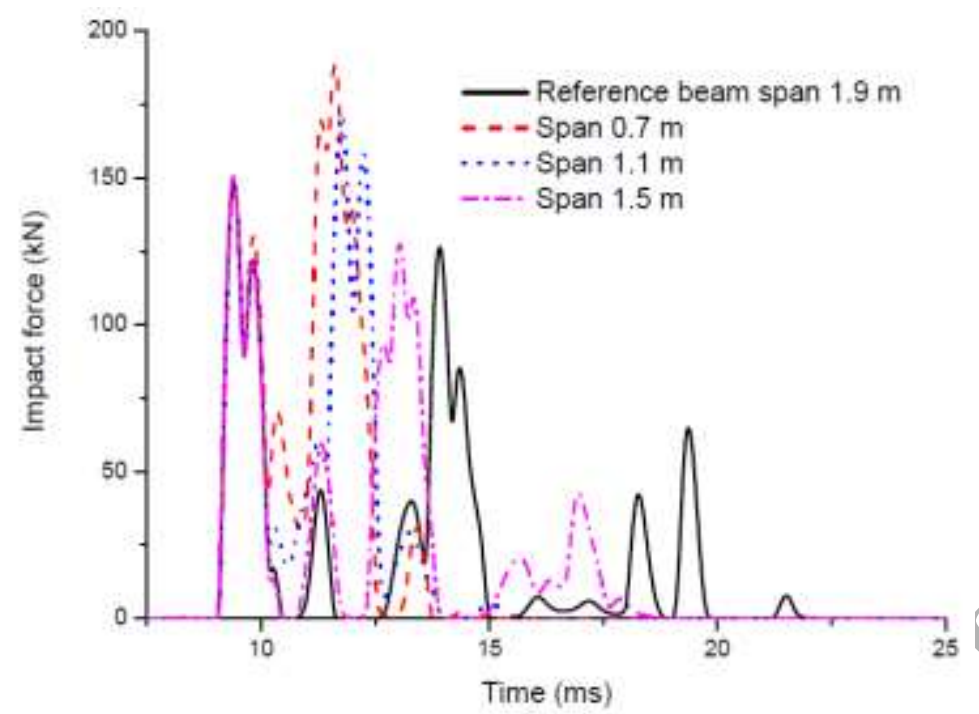

Figure 11. Impact force time histories of beams with varied span subjected to $1 \mathrm{~m} / \mathrm{s}$ impact

Furthermore, the effect of the span on the midspan displacement is also investigated and presented in Fig. 12. As shown in the previous discussion, the numerical results have shown that the span has a significant influence on the displacement of the beams. Reducing the span leads to increasing the flexural stiffness which governs the global bending action so that the displacements of the shorter beams significantly reduce. Changing the stiffness also results in changes of the natural frequency in which the shorter beams (owing to higher stiffness) have shorter duration. This observation can be clarified in the free vibration phase of the beams in Fig. 12 in which the duration of the beams reduces subsequently from the reference beam to the beams with the span of $1.5 \mathrm{~m}, 1.1 \mathrm{~m}$, and $0.9 \mathrm{~m}$, respectively.

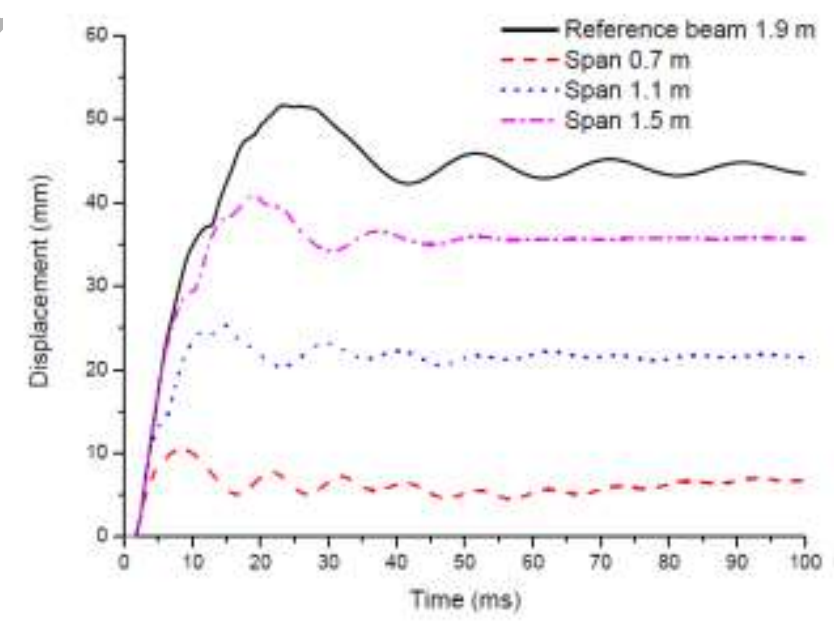


Figure 12. Displacement time histories of beams with varied span at $6.26 \mathrm{~m} / \mathrm{s}$

\section{Discussion}

The numerical simulation has shown that the span and reinforcement do not have an influence on the first impact impulse but they affect the following impact impulses and particularly the displacement. The displacement of the beams occurs primarily in the free vibration phase when the flexural stiffness and shear resistance go into effect. The first impactimpulse occurs in a much localized manner so that the boundary condition does not actually have an influence on the beam's behavior during the first impact impulse. Pham and Hao [19] investigated the effect of the boundary condition on the impact behavior of RC beams. The simply-supported and fixed-end beams in that study showed similar behavior during the first impact impulse. Meanwhile, the results from this study also indicate that the boundary does not have a noticeable influence on the beam' behavior during the first impact impulse. To verify this, a free beam is modeled to investigate the effect of no boundary condition on the impact behavior of the beams. The design of this beam is similar to the previous beam but the boundary condition is removed.

Fig. 13 shows the impact time history of the free beam against the reference beam, indicating that the two beams have no difference in the first impact impulse. It thus demonstrates that the boundary has no effect on the peak impact force when a projector is just in contact with the relatively long beam as defined in the study by Pham and Hao [19]. It is noted that a relatively long beam has a span long enough so that the stationary point has not reached the boundary at the peak impact force. The plastic strain of the free beam is also compared to that of the reference beam and the outcome is presented in Fig. 14. The plastic strain contour of the two beams shows their similarity up to $3.8 \mathrm{~ms}$ and a slight difference starts at about $5.8 \mathrm{~ms}$. The first impact impulse reaches the peak at about $1.7 \mathrm{~ms}$ and ceases at about $3 \mathrm{~ms}$ as shown in 
Fig. 13. The plastic strain of the two beams are almost identical during the first impact impulse, demonstrating the boundary condition does not affect the beam's behavior during this period. For the free beam, the projectile is separate from the beam after approximately 5 ms and the plastic strain of the free beam does not change after this moment as shown in Fig. 14. The final stage of the plastic strain of the two beams shows a significant difference. The numerical results clearly show the boundary condition does not affect the behavior of the beams during the first impact impulse. The plastic strain occurs at the impacted area underneath the load adaptor at about 1.68 - 3 ms. All beams (with different reinforcement, span and boundary condition) show a similar contour of the plastic strain before $3 \mathrm{~ms}$, indicating that other factors do not really affect the plastic strain during this period. Meanwhile, the first impulse of the impact force ends at about $3 \mathrm{~ms}$. It means that all the investigated factors do not affect the plastic strain of the beams within the period of the first impact impulse.

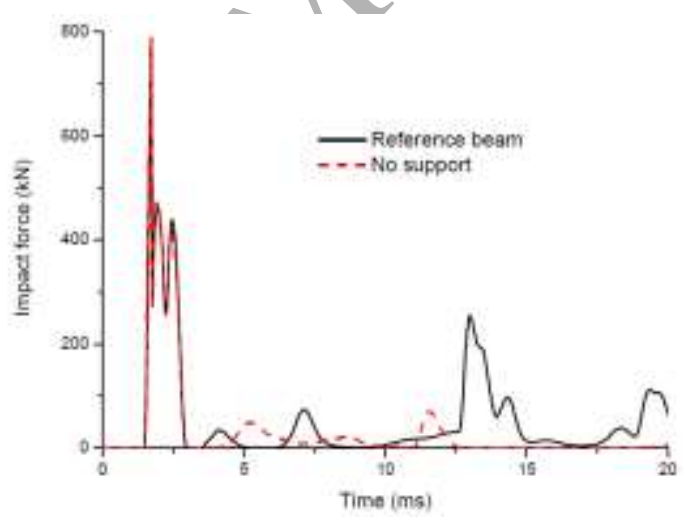

Figure 13. Impact force time histories of free beam
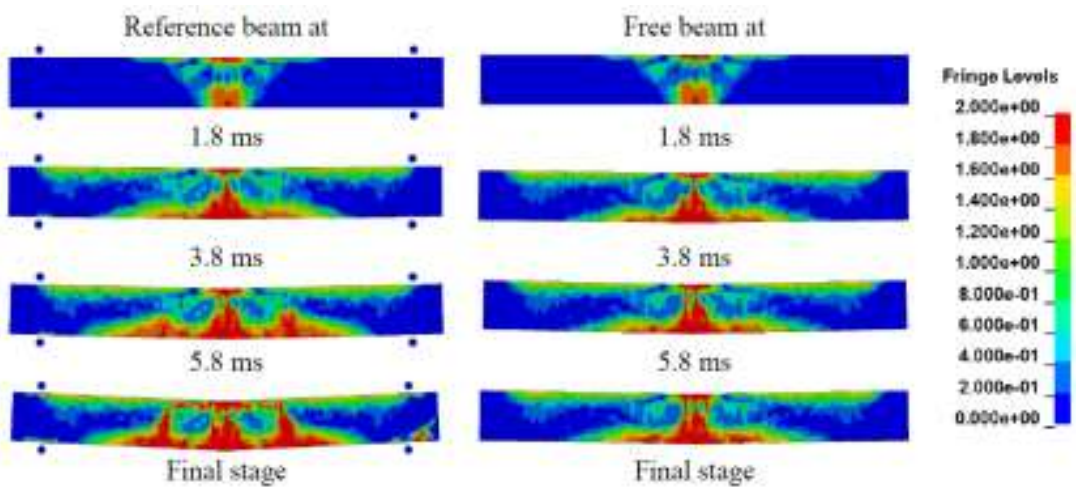

Figure 14. Plastic strain of free beam vs reference beam 
It has been showing that the span, reinforcement, and boundary condition do not affect the peak impact force. In addition, Pham and Hao [19] conducted a numerical study on the effect of the concrete strength on the impact behavior of $\mathrm{RC}$ beams. The concrete strength in that study was varied from $20 \mathrm{MPa}$ to $100 \mathrm{MPa}$ and the numerical results showed that the concrete strength does not have a considerable effect on the impact force. As reviewed by Pham and Hao [43], the maximum impact force is dominated by the beam's weight. Therefore, the concrete density is varied to investigate its influence on the impact force. There are two light weight concrete beams including $1160 \mathrm{~kg} / \mathrm{m}^{3}$ and $500 \mathrm{~kg} / \mathrm{m}^{3}$. The concrete density affects the peak impact force of the beams as shown in the impact force time history in Fig. 15. Changing concrete density from $2160 \mathrm{~kg} / \mathrm{m}^{3}$ to $1160 \mathrm{~kg} / \mathrm{m}^{3}$ has a slight effect on the impact force and this trend becomes more obvious then the concrete density is $500 \mathrm{~kg} / \mathrm{m}^{3}$.

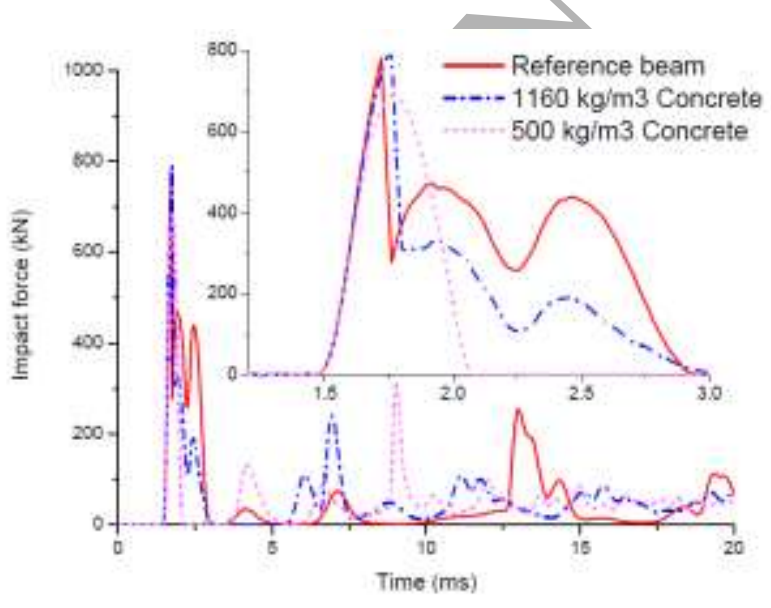

Figure 15. Impact force time histories of light weight concrete beams

\section{Proposed analytical model}

Based on the previous findings, an analytical model is proposed to predict the dynamic response of a beam subjected to impulsive loads. In general, the contact stiffness (local stiffness) governs the beam response during the first impulse phase. The plastic hinge and its formation also affect the beam's response during this stage. The global deformation of the beam at the end of the first impulse is negligible $(<5 \%)$ while the global stiffness governs the 
free vibration phase and then the final displacement of the beam. The local effects including contact stiffness and plastic hinges, therefore, are utilized to predict the impact force while the global stiffness considering the whole beam length is used to predict the beam displacement. The damping effect is also considered in the proposed model as shown in Fig. 16. The governing equation can be written as:

$$
\begin{gathered}
m_{1} \ddot{x_{1}}+k_{1}\left(x_{1}-x_{2}\right)=0 \\
m_{2} \ddot{x_{2}}+C \dot{x_{2}}+k_{2} x_{2}+k_{1}\left(x_{2}-x_{1}\right)=0
\end{gathered}
$$

where $C$ is the damping ratio of the beam. The impact force is equal to $k_{1}\left(x_{2}-x_{1}\right)$ is predicted by numerical analysis as presented previously by using LS-DYNA. The impact force predicted by different numerical simulations or analytical models can be used in this proposed model to predict the impact response of $\mathrm{RC}$ beams. It is worth mentioning that the damping effect is consider in Eq. 11 but not Eq. 10 because the force phase occurs in a very short period and the damping effect can be negligible $[6,7,9,18,19]$.

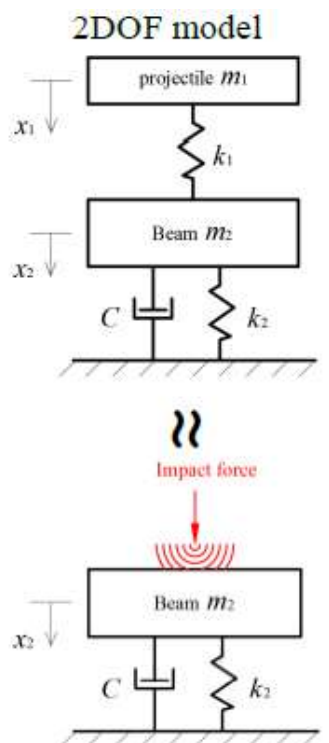

\section{Concept of displacement time history}

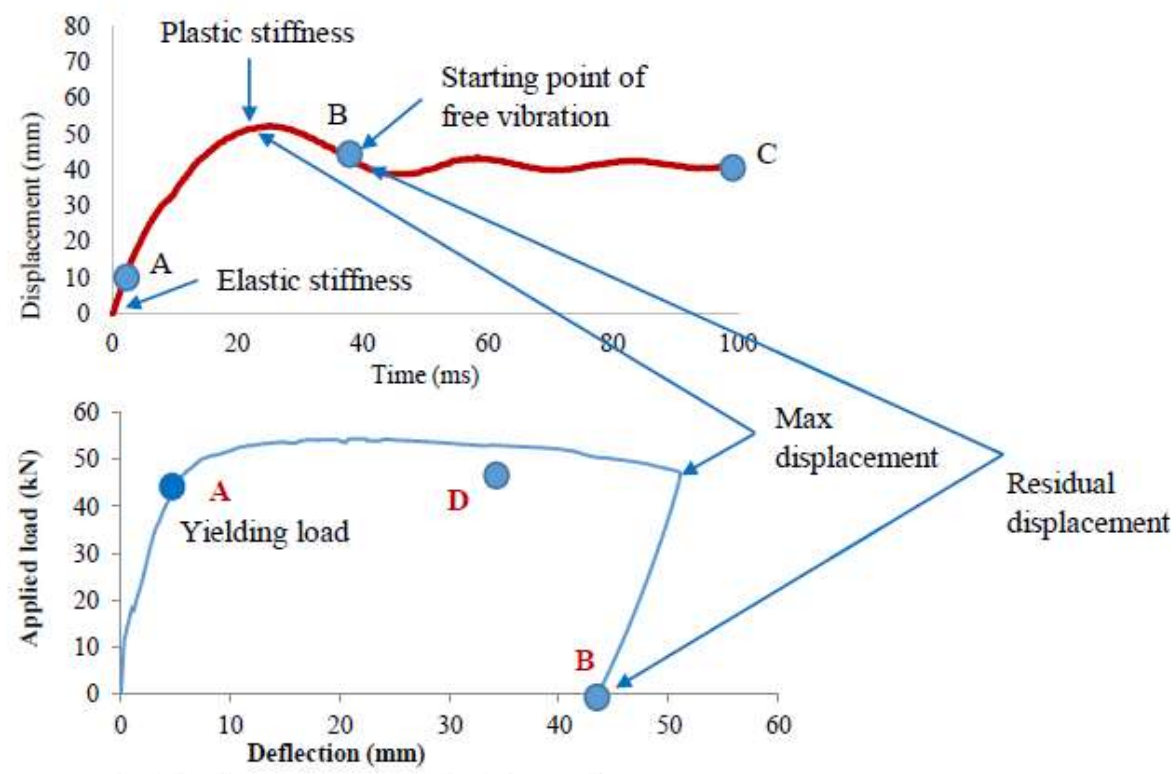

Load - displacement curve in the static test

Figure 16. 2DOF model 


\subsection{Assumptions and numerical solution}

The proposed model is used to predict the beam displacement under impulse loads and Eq. 11 can be written as:

$$
m_{2} \ddot{x}_{2}+C \dot{x}_{2}+k_{2} x_{2}=P(t)
$$

where $P(t)$ is the impact force in this study and an impulsive load in a general case. The equivalent mass of the beam $m_{2}$ is determined by equating the fundamental frequency of the actual beam to that of the spring-mass model [8]. Wu and $\mathrm{Yu}$ [8] derived the equivalent mass for a simply-supported beam as shown in the following expression:

$$
m_{2}=0.493 \rho b h L_{e}
$$

where $\rho$ is the beam density, $b$ and $h$ are respectively the width and height of the beam section, and $L_{e}$ is the effective span of the beam. Given the beam section of $150 \times 250 \mathrm{~mm}^{2}$ and the beam span of $1.9 \mathrm{~m}$, the equivalent mass is $80.8 \mathrm{~kg}$. The flexural stiffness of the simply supported beam is estimated based on the following expression:

$$
k_{2}=\frac{48 E I}{L_{e}^{3}}
$$

where $E$ is the modulus and $I$ is the moment of inertia of the beam section which takes the cracked section into consideration [44]. The initial flexural stiffness is estimated as 6.26 $\mathrm{kN} / \mathrm{mm}$. This flexural stiffness is used up to the yielding point in the static test or the typical analytical analysis. Point A defined as a stiffness transition point is located at the yielding load when the stiffness of the beam significantly reduces as shown in Fig. 16. The loaddisplacement curve in this figure is adopted from the previous study by Pham and Hao [28]. Meanwhile, the residual displacement in the proposed model is dependent on the maximum 
displacement and it can be determined both from the experimental test or analytical analysis. In this study, the displacements at Points $\mathrm{A}$ and $\mathrm{B}$ are about $5 \mathrm{~mm}$ and $44 \mathrm{~mm}$, respectively. After the instant of Point A, the beam stiffness continuously reduces from the elastic stiffness at Point $\mathrm{A}$ to the lowest value at the maximum displacement Point D. The stiffness representing for this period is considered at the average value. The average stiffness representing for the period from A to B in Fig 16 is $1.25 \mathrm{kN} / \mathrm{mm}$ which is equal to $20 \%$ of the initial stiffness. The damping ratio is assumed to be $3.5 \%$ and it is estimated as $3.4 \mathrm{Ns} / \mathrm{m}$. The proposed model is summarized in three stages as follows:

$$
\begin{aligned}
& m_{2} \ddot{x_{2}}+C \dot{x_{2}}+k_{2_{-} \text {elastic }} x_{2}=P(t) \text { for } O A \\
& m_{2} \ddot{x}_{2}+C \dot{x_{2}}+k_{2_{2} \text { plastic }} x_{2}=P(t) \text { for } A B \\
& m_{2} \ddot{x}_{2}+C \dot{x}_{2}+k_{2_{\text {pplastic }}}\left(x_{2}-x_{2}^{\text {residual }}\right)=0 \text { for } B C
\end{aligned}
$$

The central difference algorithm is adopted to solve Eq. 15, such as at time t:

$$
\begin{aligned}
& \dot{x}_{2}=\frac{1}{2 \Delta t}\left(x_{2}^{t+\Delta t}-x_{2}^{t-\Delta t}\right) \\
& \ddot{x_{2}}=\frac{1}{\Delta t^{2}}\left(x_{2}^{t+\Delta t}-2 x_{2}^{t}+x_{2}^{t-\Delta t}\right)
\end{aligned}
$$

This solution can be solved with initial starting conditions at $t=0: \dot{x}_{2}=0, P(t)=0, \ddot{x}_{2}=0$, and $x_{2}^{-\Delta t}=-\Delta t \times 0=0$. The solution starts with determining $x_{2}^{t+\Delta t}$, the corresponding impact force is from the numerical results, and the $\dot{x}_{2}$ and $\ddot{x}_{2}$ are determined from Eqs. 16-17.

\subsection{Verification of the proposed analytical model}

Analytical results from the proposed model are compared with those from the experimental tests and numerical simulation as shown in Fig. 17. The analytical results match the experimental and numerical results well. The differences in the peak responses and the 
response stiffness can be attributed to neglecting local damage in the beam caused by impact in the analytical model. After the peak displacement, the free vibration of the analytical model stops earlier than those of the experimental and numerical results. This discrepancy is dependent on the damping effect which is not understood well under impact loads. Moreover, the analytical result of the velocity of the beam at the midspan is compared with that from the numerical model and presented in Fig. 18. The analytical results match with those from the numerical modelling well. The above verification has demonstrated that the proposed analytical model predicts the impact response of RC beams with reasonable accuracy.

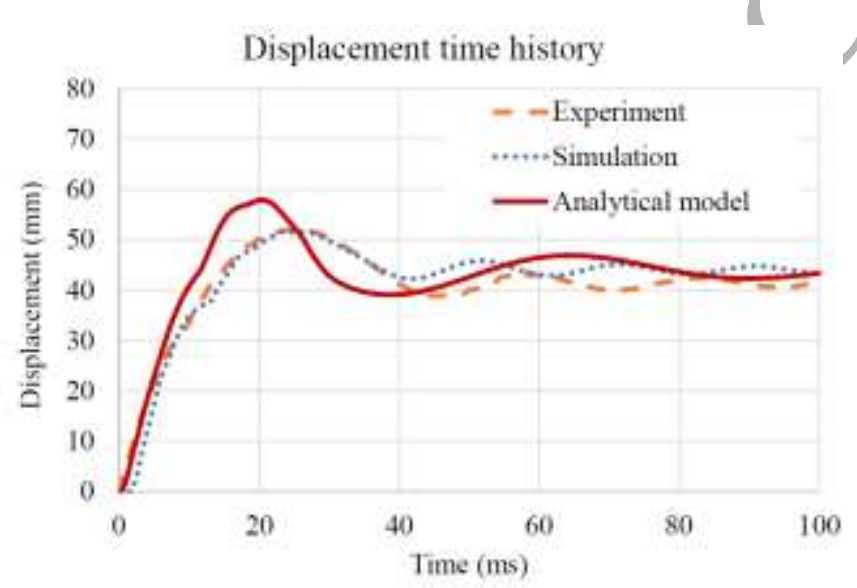

Figure 17. Verification of the analytical model

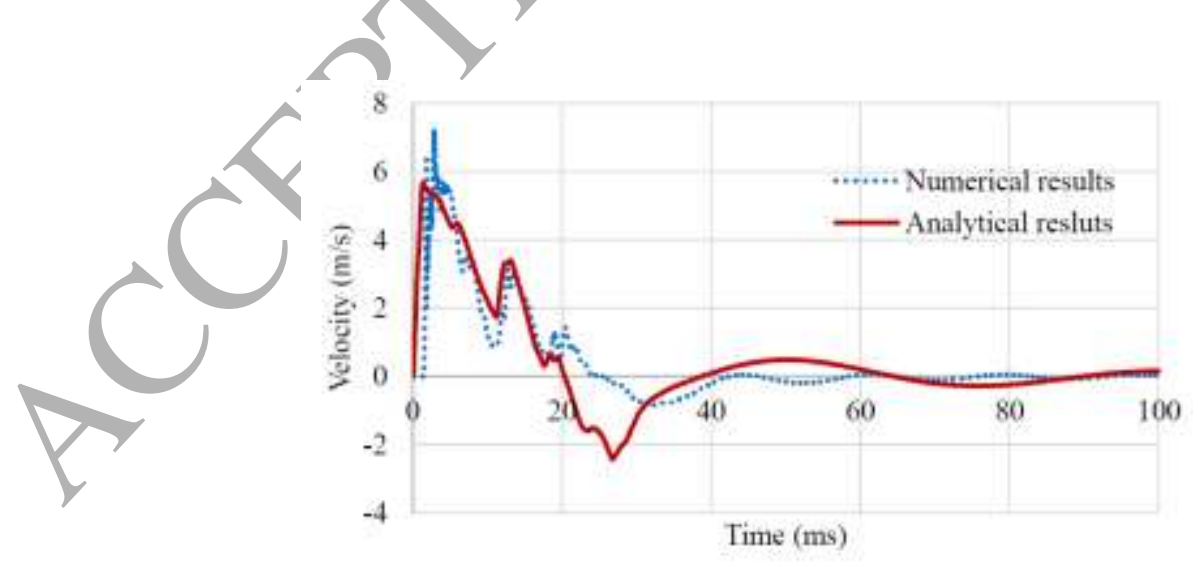

Figure 18. Velocity of the beam - analytical vs numerical models

\section{Conclusions}


This study numerically and analytically examines the effect of the stiffness on the impact behavior of RC beams. An analytical model is proposed to predict the impact response of RC beams subjected to impulsive loads. The findings in this study can be summarized as follows:

1. Changing the stiffness of a beam by varying the span and reinforcement does not affect the behavior of the RC beams during the first impact impulse. However, they change the displacement, failure mode, and reaction forces of these beams at later stages.

2. The free beam has a similar impact behavior as compared to the reference beams up to the instant when the first impulse ceases.

3. The beam response is divided into two phases including the force phase and the free vibration phase. The force phase is governed by the local stiffness while the global stiffness affects the later one.

Finally, using the stiffness of a beam in a spring-mass model to determine the impact force of the first impulse may not provide an accurate prediction. The impact force may be properly estimated by using contact algorithms, for example, those implemented in LS-Dyna.

\section{Acknowledgement}

The authors acknowledge the financial support from Australian Research Council (ARC) and Curtin University.

\section{References}

[1] Luccioni BM, Aráoz GF, and Labanda NA, Defining erosion limit for concrete, Int. J. Protect. Struct. 2013;4 (3):315-340.

[2] Villavicencio R and Guedes Soares C, Numerical modelling of the boundary conditions on beams stuck transversely by a mass, Int. J. Impact Eng. 2011;38 (5):384-396.

[3] Jiang H, Wang X, and He S, Numerical simulation of impact tests on reinforced concrete beams, Materials \& Design 2012;39:111-120. 
[4] Ožbolt $\mathbf{J}$ and Sharma A, Numerical simulation of reinforced concrete beams with different shear reinforcements under dynamic impact loads, Int. J. Impact Eng. 2011;38 (12):940-950.

[5] Hao H, Predictions of Structural Response to Dynamic Loads of Different Loading Rates, Int. J. Protect. Struct. 2015;6 (4):585-606.

[6] Abrate S, Modeling of impacts on composite structures, Compos. Struct. 2001;51 (2):129138.

[7] Olsson R, Mass criterion for wave controlled impact response of composite plates, Composites Part A: Applied Science and Manufacturing 2000;31 (8):879-887.

[8] Wu KQ and Yu TX, Simple dynamic models of elastic-plastic structures under impact, Int. J. Impact Eng. 2001;25 (8):735-754.

[9] Bischoff PH, Perry SH, and Eibl J, Contact force calculations with a simple spring-mass model for hard impact: A case study using polystyrene aggregate concrete, Int. J. Impact Eng. 1990;9 (3):317-325.

[10] Dragos $\mathrm{J}$ and $\mathrm{Wu} \mathrm{C}$, Interaction between direct shear and flexural responsés for blast loaded one-way reinforced concrete slabs using a finite element model, Eng. Struct. 2014;72:193-202.

[11] Low HY and Hao H, Reliability analysis of direct shear and flexural failure modes of RC slabs under explosive loading, Eng. Struct. 2002;24 (2):189-198.

[12] Krauthammer T, Bazeos N, and Holmquist T, Modified SDOF analysis of RC box-type structures, J. Struct. Eng. 1986;112 (4):726-744.

[13] Ross TJ and Krawinkler H, Impulsive direct shear failure in RC slabs, J. Struct. Eng. 1985;111 (8):1661-1677.

[14] Lee E and Symonds PS, Large plastic deformations of beams under transverse impact, Journal of Applied Mechanics 1952;19 (3):308-314.

[15] Yu T, Yang J, and Reid S, Interaction between reflected elastic flexural waves and a plastic 'hinge' in the dynamic response of pulse loaded beams, Int. J. Impact Eng. 1997;19 (5):457-475.

[16] Johnson W, Impact strength of materials, Edward Arnold London, 1972.

[17] Jones N, Structural impact, Cambridge university press, 2011.

[18] Pham TM and Hao H, Plastic hinges and inertia forces in RC beams under impact loads, Int. J. Impact Eng. 2017;103:1-11.

[19] Pham TM and Hao H, Effect of the plastic hinge and boundary condition on the impact behaviour of RC beams, Int. J. Impact Eng. 2017;102:74-85.

[20] Biggs JM, Introduction to structural dynamics, McGraw-Hill College, 1964.

[21] Sha $\mathrm{Y}$ and Hao $\mathrm{H}$, A simplified approach for predicting bridge pier responses subjected to barge impact loading, Adv. Struct. Eng. 2014;17 (1):11-23.

[22] Gao ZY, Yu TX, and Lu G, A study on type II structures. Part I: a modified onedimensional mass-spring model, Int. J. Impact Eng. 2005;31 (7):895-910.

[23] Krauthammer T, Assadi-Lamouki A, and Shanaa H, Analysis of impulsively loaded reinforced concrete structural elements-II. Implementation, Computers \& structures 1993;48 (5):861-871.

[24] $\mathrm{Xu} \mathrm{J}, \mathrm{Wu} \mathrm{C}$, and $\mathrm{Li} \mathrm{Z}-\mathrm{X}$, Analysis of direct shear failure mode for RC slabs under external explosive loading, Int. J. Impact Eng. 2014;69:136-148.

[25] Cotsovos D, Stathopoulos N, and Zeris C, Behavior of RC beams subjected to high rates of concentrated loading, J. Struct. Eng. 2008;134 (12):1839-1851.

[26] Saatci S and Vecchio FJ, Effects of shear mechanisms on impact behavior of reinforced concrete beams, ACI Struct. J. 2009;106 (1):78-86.

[27] LS-Dyna, keyword user's manual V971, 2Livermore Technology Software Corporation, Livermore, CA 2012:2994. 
[28] Pham TM and Hao H, Behavior of fiber reinforced polymer strengthened reinforced concrete beams under static and impact loads, Int. J. Protect. Struct. 2017;8 (1):1-22.

[29] Pham TM and Hao H, Impact behavior of FRP-strengthened RC beams without stirrups, J. Compos. Constr. 2016;20 (4):04016011.

[30] Pham TM, Hao Y, and Hao H, Sensitivity of impact behaviour of RC beams to contact stiffness, International Jounral of Impact Engineering 2018;112:155-164.

[31] Jiang $\mathrm{H}$ and Zhao J, Calibration of the continuous surface cap model for concrete, Finite Elements in Analysis and Design 2015;97:1-19.

[32] Tu Z and Lu Y, Evaluation of typical concrete material models used in hydrocodes for high dynamic response simulations, Int. J. Impact Eng. 2009;36 (1):132-146.

[33] Yonten K, Manzari MT, Marzougui D, and Eskandarian A, An assessment of constitutive models of concrete in the crashworthiness simulation of roadside safety structures, International Journal of Crashworthiness 2005;10 (1):5-19.

[34] Malvar LJ, Crawford JE, Wesevich JW, and Simons D, A plasticity concrete material model for DYNA3D, Int. J. Impact Eng. 1997;19 (9):847-873.

[35] Chen W, Hao H, and Chen S, Numerical analysis of prestressed reinforced concrete beam subjected to blast loading, Materials \& Design 2015;65:662-674.

[36] Shi Y, Hao H, and Li Z-X, Numerical derivation of pressure-impulse diagrams for prediction of RC column damage to blast loads, Int. J. Impact Eng. 2008;35 (11):1213-1227.

[37] Hao Y and Hao H, Influence of the concrete DIF model on the numerical predictions of RC wall responses to blast loadings, Eng. Struct. 2014;73:24-38.

[38] Malvar LJ, Review of static and dynamic properties of steel reinforcing bars, ACI Mater. J. 1998;95 (5):609-614.

[39] Malvar LJ and Ross CA, Review of strain rate effects for concrete in tension, ACI Mater. J. 1998;95 (6):735-739.

[40] Malvar LJ and Crawford JE, Dynamic increase factors for concrete, in, DTIC Document, 1998.

[41] Hao Y, Hao H, Jiang GP, and Zhou Y, Experimental confirmation of some factors influencing dynamic concrete compressive strengths in high-speed impact tests, Cem. Concr. Res. 2013;52:63-70.

[42] MacGregor JG, Reinforced concrete: mechanics and design, Prentice Hall, Upper Saddle River, N.J, 2005.

[43] Pham TM and Hao H, Prediction of the impact force on RC beams from a drop weight, Adv. Struct. Eng. 2016;19 (11):1710-1722.

[44] Warner RF, Foster SJ, and Kilpatrick AE, Reinforced concrete basics: analysis and design of reinforced concrete structures, Pearson Education Australia, 2007. 
Graphical abstract
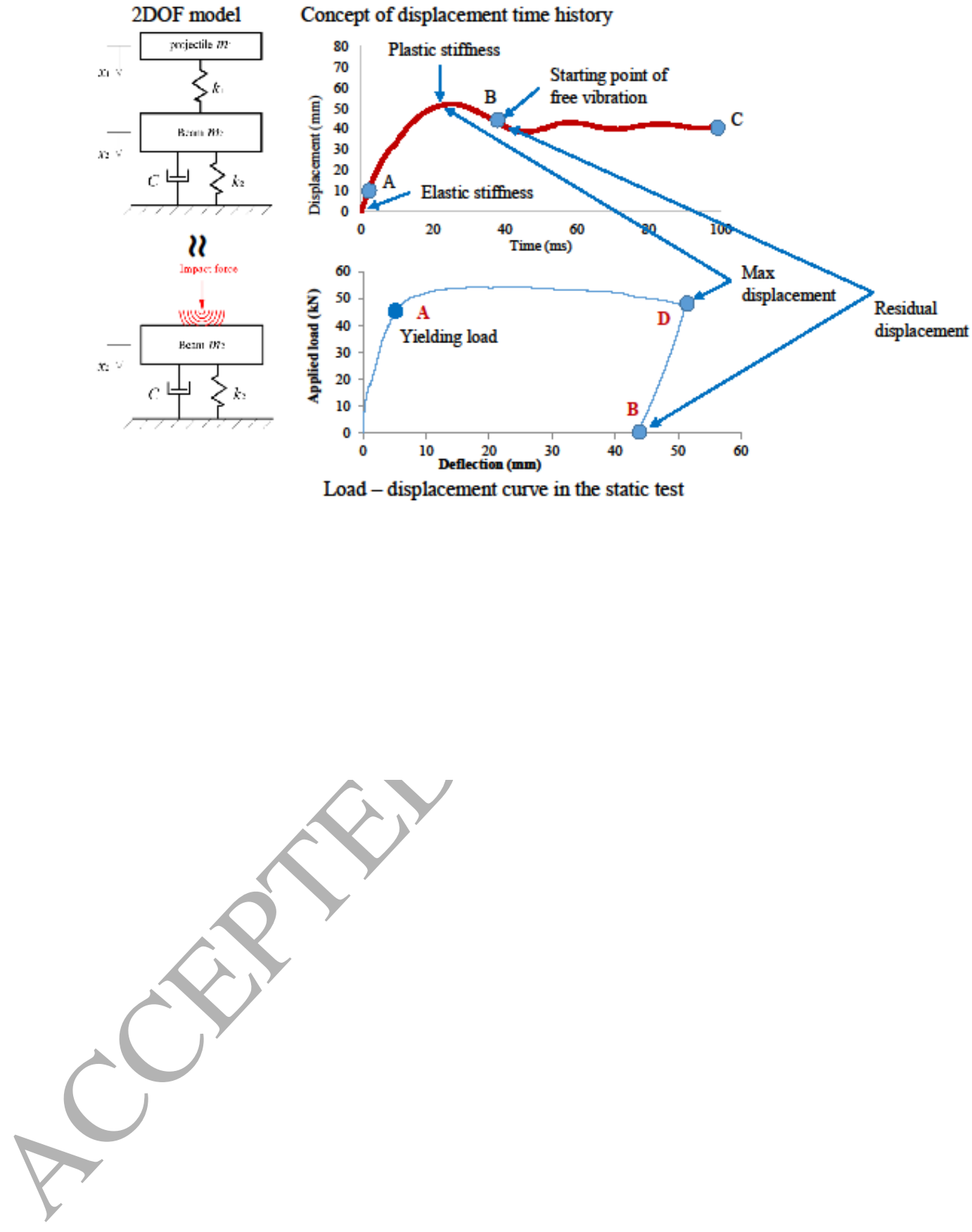